\title{
The Whiteness of Redmen: Indigenous Mascots, Social media and an Antiracist Intervention
}

\author{
Sheelah McLean \\ University of Saskatchewan \\ sheelah.mclean@usask.ca
}

\author{
Alex Wilson \\ University of Saskatchewan

\section{Erica Lee} \\ University of Saskatchewan
}

\begin{abstract}
Resistance to the use of Indigenous themed mascots in North America has taken a variety of forms over the past several decades. This paper describes and analyses how a new vehicle for resistance, social media, can be integral to dismantling and eradicating racist images of Indigenous peoples. Specifically, this paper focusses on one campaign that questioned a high school sports mascot and team named the "Redmen". By using examples from social media, the authors demonstrate how White settlers came to rely on the mascot imagery as a way to position themselves as superior and to regulate representations of Indigeneity. The authors' analysis posits that the mascot is in itself a form of racialised colonial violence and they discuss how the name and mascot were protected by and through white settler surveillance and control. To intervene in this discourse of superiority and regulation, the paper describes how an anti-racist approach was used to design a social media campaign that built mass critical consciousness and a network of support within the community. The social media campaign coincided with and rallied support from the grassroots Indigenous Movement, Idle No More. The larger joint effort strategically and effectively redirected the public and critical focus to how the "Redmen" name and logo and other racist Indigenous mascots become normalised. Increased knowledge via social media catalysed a shift in public opinion which ultimately leads to retirement of the team name, logo and mascot.
\end{abstract}

Keywords: Social media; Indigenous mascots; Indigenous resistance; White supremacy; Anti-racist education.

\section{Introduction}

The problematics of Indigenous mascots have been a topic of academic analysis and a focus for resistive practices in North America for decades. Although there have been varied approaches to understanding and positioning resistance, scholars such as Francis (1992) and King (2004) use critical race theory and anti-racist theory to explain the production, regulation and control of images of Indigenous peoples in a white settler context. That context is produced through a history of colonial policies and practices that exalt white settler identities and institutions, while denying Indigenous peoples' self-determination. This paper will focus on a social media campaign, informed by anti-racist theory that sought to remove a high school sports team's name-the "Redmen"-and the associated mascot. Analysis of the \#ChangeRedmen campaign, and the subsequent resistance to it, reveals how colonial discourses are enacted by individuals and communities on (but not limited to) the Canadian Prairies. In the end, the "Redmen" mascot was retired. The \#ChangeRedmen campaign's use of social media, coinciding and in conjunction with the power of the social media driven grassroots movement Idle No More, was integral to a successful intervention to dismantle and eradicate the use of the team name, mascot, and logo.

Indigenous mascots in and of themselves, can be understood as a form of racialised colonial violence that is created and protected by white settler surveillance and control. Staurowsky (2007) contends that Indigenous mascots are a white invention defended by institutions that 
are predominantly white. The Indigenous mascot becomes a symbol or is a text that can be read and understood as embodying numerous codes of white settler colonialism both past and present (Farnell 2004). These codes draw upon discourses such as the 'Indian warrior' (Fryberg et al. 2008) and the 'noble savage' (NCAI 2013), thereby reinforcing stereotypes of Indigenous men as violent and threatening. Mascots signify stock tropes of Indigeneity and masculinity that freeze Indigenous people in the colonial era (Leavitt et al. 2015). They collapse hundreds of diverse Indigenous nations into one caricature with characteristics such as clothing and feathers that belong only to some Plains nations (Farne 2004). These reductive and often paradoxical representations are used by institutions such as schools and the mainstream media to regulate Indigeneity in a white settler state.

The \#ChangeRedmen social media campaign provided a space for Indigenous and antiracist pedagogy to be enacted while being lead by Indigenous women and two-spirit people. Antiracist theory, drawing from critical theory and feminist theory, contends that our identities are constructed through discursive formations that position us in particular ways. Dei (1995, p.14) describes integrative antiracism as an examination of the interrelated components of gender, sexual orientation, class and race that are "mediated in people's historical and everyday lived experiences" and contends that understanding these relationships are necessary for progressive learning and social change. With relations of power at the center of analysis the focus shifts to how identity-making practices are produced through discourses, the differential ways people are positioned by these discourses, and how these formations are reified in particular contexts (McLean 2016).

In the colonial context, Indigenous peoples have been marginalised by white institutions, such as schools and the mass media. Social media in its increased accessibility to Indigenous peoples provides a public space where people can openly challenge stereotypical representations thereby disrupting and circumventing institutional regulation and control. As Indigenous scholar Bronwyn Carlson (2016) states, "[s]ocial media has changed the nature of communication with sites like Facebook and Twitter becoming the primary sources of communication where Indigenous people can find out what is happening in our networks and in the world." Recent research indicates that Indigenous people are "using social media at rates 20\% higher than non-Indigenous people" (Carlson \& Frazer 2016, p.218). Through social media Indigenous Peoples can narrate their own stories, produce their own symbols of representation, and challenge racialising practices.

\section{The \#ChangeRedmen Campaign}

Although the use of Indigenous mascots has decreased over the past decade (NCAI 2013) the topic of "mascotting" has become increasingly visible across North America. The term "mascotting" was introduced by cultural critic Dave Zirin in his 2015 interview with Erica Lee and Suzan Shown Harjo (Zirin 2015). As King (2004, p.194) suggests, "Individuals and organizations, from high-school students and teachers to [Indigenous rights movements], passionately and aggressively have contested mascots, forcing public debates and policy changes". Various educational institutions have revised their use of the imagery, while others have retired their mascots. As the National Collegiate Athletic Association (NCAI) (2013, p.6) reports, "over 2,000 'Indian' references in sports have been eliminated during the past 35 years". The most notable instances at the post-secondary level are the retirement of the Stanford University Indian and the Dartmouth College Indian (King 2015; USA Today 2013). At the secondary school level, the Minnesota Board of Education (Education Week 1998) and the Los Angeles Unified School District (Los Angeles Times 2013) have both enacted policies to ban or change racist mascots. Several Canadian junior and high school teams have recently opted to change their names following public concern. In 2013, the Nepean "Redskins" youth football team in Ottawa changed its name to the Nepean Eagles after a human rights complaint (Schnurr 2013). Shortly after the Western Canada High School in Calgary dropped its "Redmen" name and logo after consulting with school board Elders (CBC News January 12, 2014). 
The authors of this article worked on the \#ChangeRedmen campaign from 2010 until its successful completion in 2014. Two of the authors, Sheelah McLean and Erica Lee first met when Lee was a student in several of McLean's classes in her senior year of high school. They began to work together on social justice campaigns and speaking engagements both inside and outside of school. McLean had just completed her Master's Degreein antiracist education and chose to share excerpts from Daniel Francis' (1992) book, The Imaginary Indian: The Image of the Indian in Canadian Culture. The purpose of assigning the Francis chapters was to invite students to problematise and critique the issue of racist school mascots. Although some of the students exhibited discomfort with the book, the readings provided important discussion points and insights and resonated strongly with Lee. McLean invited Cree scholar Alex Wilson to work with them on the campaign where Wilson provided mentorship and guidance in antiracist theory and technical support for the social media campaign.

As an editor of the school newspaper, Erica Lee decided to publish an article issuing a challenge to change the mascot and team name from the "Redmen" to the "Spidermen", noting that the colour red would remain. Although she wrote the piece in a humorous tone, she recalls the backlash from students and teachers who told her they were discomforted by the article. Lee created the first Facebook page for the \#ChangeRedmen Campaign a few years after she graduated from the high school. She continues to discuss the significance of removing Indigenous mascots, in her blog Moontime Warrior:

Like racist costumes and stereotypes, far from being just a name, the Bedford Road "Redmen," Washington "Redskins," Moose Jaw "Warriors," and Chicago "Blackhawks" are products of white supremacy: stories told about us while excluding our voices. While it seems like a small issue on the surface, challenging inaccurate depictions of Native people is a step toward a better life (Lee 2014).

State-sanctioned racist stereotypes such as Indigenous mascots in schools justify and normalise inequality. Racist symbols reify notions of biological difference and determinism which in turn entrench a racial hierarchy (Gould 1981). These discourses of racial difference, and the idea that white settlers are dominant because they are genetically predisposed to intelligence, civility, hard work ethics and other attributes mask the ways in which access to social and political power are determined through racial significations. Groups that are Othered are constructed as biologically or culturally different and deficient, when injustices are committed daily. This cycle normalises oppression in order to maintain systems of dominance (Dei et al. 2005). Strong (2004, p.83) states that the practice of appropriating Indigenous culture is part of the normalisation that serves to "exclude contemporary Native Americans from full citizenship by treating them as signs rather than as speakers, as caricatures rather than as players and consumers, as commodities rather than citizens." Indigenous people become singular objects rather than agents of their own social and political lives. Sports fans and students who 'play Indian' by adorning their bodies with paint and feathers become part of the text or performance of the mascot, further normalising a racial hierarchy, dominance and oppression. As Staurowsky argues:

One of the harms of Native American sport team imagery is the day-to-day, easily accessible instruction it provides in how to inappropriately claim symbolic American Indian identity without thought to the individual and collective consequences of doing so. As a tool of social control, non-American Indians become adept at misappropriating without conscience or consideration while creating mass confusion as to who is an Indian (2007, p.66).

This appropriation is integral to white settler's erasure of Indigenous peoples' legitimate reclamations of land and sovereignty. These performances are produced through the white imaginary and desire for legitimacy and belonging on lands that are stolen.

Research suggests that Indigenous mascots are harmful to society and studies have examined how Indigenous mascots create a racially hostile environment (Baca 2004; Farnell 2004; King 2004; Staurowsky 2007). As a result of research and increased pressure from Indigenous peoples and human rights organisations, several organisations in the United States have 
passed resolutions calling for a ban of Indigenous mascots and related symbols by schools and sport teams (American Psychological Association 2005; Inter-Tribal Council of the Five Civilized Tribes 2001; U.S. Commission on Civil Rights 2001). The American Psychological Association (APA) (n.d.), one such organisation, made a public statement declaring the harmful impacts of sexist and racist mascots and logos on Indigenous peoples, racialised minorities, and women and called for "the immediate retirement of all American Indian mascots, symbols, images, and personalities by schools, colleges, universities, athletic teams, and organizations." APA's position was important because not only did it demand the retirement of mascotting, it also made the direct link to violence and degradation of American Indians and a connection to the internalisation of that violence to self-esteem (APA 2005). APA's position is supported through policy in other organisations. In August of the same year, the National Collegiate Athletic Association (NCAA) in the United States announced a policy that would require colleges and universities with Native American mascots and imagery to refrain from displaying those during NCAA-sponsored events (NCAA 2005). This policy enacted sanctions on schools that did not comply with the change stating that institutions with this imagery would be ineligible to host NCAA championships starting in 2006 (Staurowsky 2007). In spite of the extensive and thorough research that was provided showing the racism endemic in the creation and use of Indigenous mascots, each of these associations received backlash from the public and institutions that challenged their recommendations. Farnell (2004) suggests that this resistance is a way to maintain schools and sports institutions as white domain.

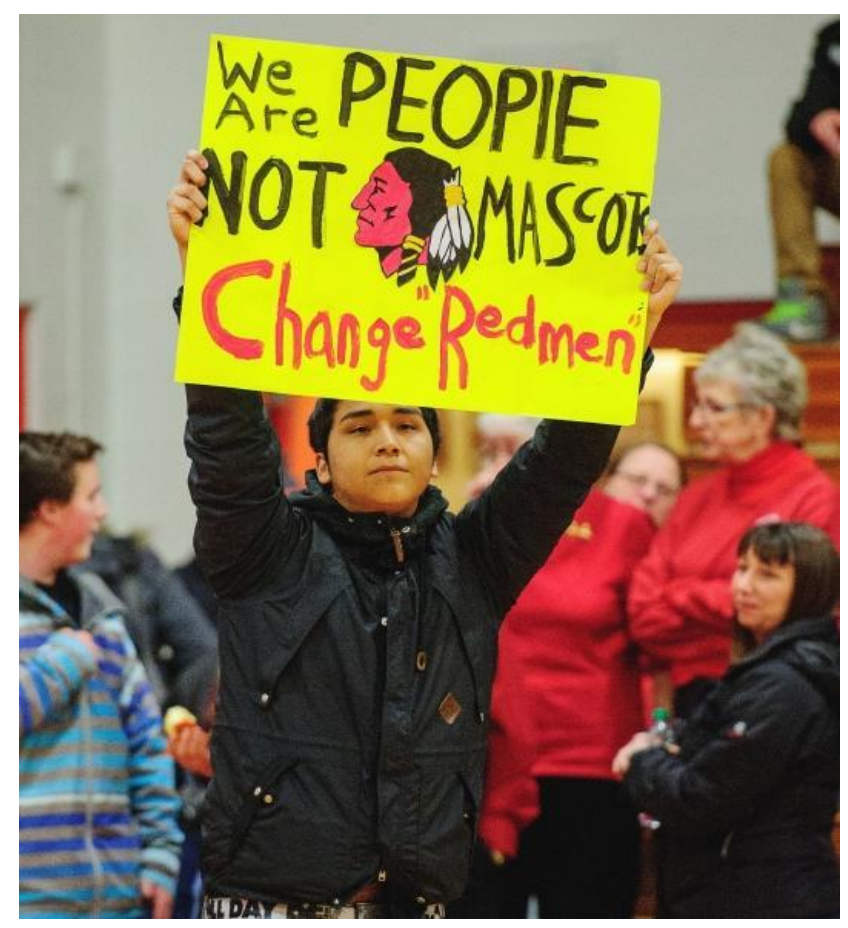

Figure 1: Andre Bear at the BRIT Tournament. Photo credit Star Phoenix

\section{3 'The Creepy White Gaze': Settler Pleasure and Control}

In a colonial context, white settler identity is co-constructed with Indigeneity, so that the images of Indigenous peoples come to represent everything that white settlers are not (Francis 1992; Said 1979). Dei et al. (2005, p. 93) suggests that, "[w]hat originally grew out of the colonial gaze has become cemented in the construction of the other and our firm knowledge of what is and what is not. What we are and what we are not". Whiteness is constructed on discourses of civility, domestication, superior work ethic, and ingenuity (Thobani 2011). White settlers imagine that state rights are acquired because of their own intrinsic goodness, rather than colonial practices of domination. In fact, state rights were accorded on the basis of how the national public was produced in relation to gender, race, sexuality, class, and other identity 
markers (McLean 2016). These narratives of white superiority define both the Canadian national identity and determine the policies and practices which shape Canada's social and political landscape. In stark contrast to white settlers, Indigenous peoples have been predominantly represented as primitive, savage, and wild. Often Indigenous peoples are constructed as part of nature and wilderness, which is in keeping with the alternate use of animal imagery as school and team mascots (Francis 1992). The ongoing racialisation and dehumanisation of Indigenous peoples through texts such as mascots is necessary for normalising white supremacy. White settlers come to rely on Indigenous mascots as a way to both understand themselves as superior and regulate representations of Indigeneity. In this way, white settlers maintain control over representations of Indigeneity as a technique for continuous self-constitution.

Drawing from Foucault's (1995) concept of surveillance, Sterzuk and Mulholland (2011) use the term 'creepy white gaze' to interrogate the relationship between white identity and power. Foucault (1995) contends that power lies at the root of the gaze, which is produced through disciplinary and regulative acts that exercise control and dominance over the bodies of those who are othered. As Foucault (1995, p220) contends:

...to substitute for a power that is manifested through the brilliance of those who exercise it, a power that insidiously objectifies those on whom it is applied; to form a body of knowledge about these individuals, rather than to deploy the ostentatious signs of sovereignty.

In terms of what the gaze accomplishes, Warren (2005) suggests that by virtue of the repetitive act of looking, the gaze constitutes race as a category of difference. White settlers derive pleasure from Indigenous mascots because they are (re)constituted as both human and superior through the public rituals that celebrate and reproduce this racial distinction. The power whites wield over representational texts such as Indigenous mascots provides a playground for mastery over racialised objects (Sterzuk \& Mulholland 2011). White settlers socialised into dominance will resist retiring the mascot because it is a blow to who they think they are, and their desire to control Indigeneity. Indigenous people continue to resist by exerting sovereignty and self-determination in all aspects of their lives, including representation. As Lee (2014) states:

Refusing to put up with racist sports team names, mascots, and logos is a declaration that we are more than disposable stereotypes with tomahawks in John Wayne stories where the injuns always lose. We are teachers, students, lawyers, writers, artists, musicians, workers, and activists. We are capable of doing well in schools and universities while still holding on to our traditional knowledge-recognizing that the two are not incompatible, and that Indigenous knowledge ought to be (and already is) present in Western academic institutions. We are members of unique communities and we are individuals.

The \#ChangeRedmen social media campaign was intentional. We sought to 'shift the gaze' (hooks 1991; Mulvey 1973; Razack 1998), in other words, shine a very public and critical lens on white settler (and implicitly patriarchal) discourses that normalise the use of racist Indigenous mascots. The backlash our campaign initially received on social media and in the wider community was often framed with emotional rhetoric such as "honor," "school pride," "tradition," and a personal connection to school memories that the mascot somehow embodied. These iterations are code words that make the violence seem more palatable and maintain the innocence of white settlers. The emotional investment that so many white settlers had in the racist mascot is a protection of their whiteness and white supremacy as a colonial system of power. The silencing the student-author, Lee, experienced over her letter in the newspaper was a microcosm of the eventual wave of violence she and others involved in the campaign would experience online once we launched the social media campaign. 


\section{The Dynamics of Online Antiracism Campaigning: Shifting the Gaze}

In March 2011, the campaign started a Facebook page called 'Bedford Road 'Redmen,' It's Time for Change". Within a few days, the page had received local and even national media attention. Members of the campaign had ongoing discussions regarding strategies for using online education as a mode of intervention.

Effective strategies include:

1. Focus on brief, clear messages as part of the intervention. One such message was "We are people, not mascots". Many of these messages were also hashtags (\#PeopleNotMascots) that allowed us to track usage and gain momentum as people started using them. The hashtags were portable between Facebook, Twitter, Instagram and multiple other social media.

2. Avoid the "Oppression Olympics". We decided to avoid comparisons to other racialised groups as mascots. Although King (2004) suggests that these comparisons may have been a successful strategy in the past, they can be problematic. Comparisons between racialised groups are sometimes called the "Oppression Olympics," (origin unknown) whereby oppressed groups are forced into competing positions rather than emphasising how dominance and oppression are structured in a way that produces differential effects. Comparing the Indigenous mascot to other racialised groups also replicates more images of racist mascots (defeating our goal), and displaces the broader colonial frameworks and racial formations that specifically impact Indigenous peoples.

3. Draw from antiracist theory and pedagogy in order to maintain a consistent message in the campaign. We held local teach-ins to supplement our social media campaign in the form of a panel at the local university and a class at the Peoples Free University to further educate the public.

4. Have several spokespeople represent the campaign on social media. To disrupt the individualisation of the campaign onto particular organisers, as well as to highlight the reality that this was a large movement of people we ensured that a variety of voices and faces were visible. And,

5. Connect to emerging and existing similar campaigns and/or solidarity movements.

Each of these decisions was made in order to build the campaign, educate the public, build a supportive network and to redirect and dissipate some of the violent backlash.

The issue of racist Indigenous mascots became a national conversation in Canada as the Idle No More (INM) movement and the human rights case against the Nepean "Redskins" in Ontario gained traction in the media. The Idle No More movement expertly used social media and non-violent direct action to raise critical consciousness regarding Indigenous selfdetermination and land protections. Idle No More organisers created a web of networks which included over four hundred Facebook pages and event pages, including a Causes page with over 150,000 members (Crowe \& Wilson 2015; McAdam, Wilson, \& Case 2016). We also created an Idle No More website and several twitter pages, where we could highlight pictures of the events and actions such as protests, gatherings, ceremonies and round dances happening across the globe. This strategy connected people to the movement, and provided a platform for organising with others in the movement.

Idle No More quickly exploded into a global movement and is considered the largest Indigenous rights movement in North America (Kino-nda-niimi Collective 2014). The \#ChangeRedmen campaign in the small prairie city of Saskatoon now had a very public spotlight and support from across Canada and beyond. The scope of a public social media campaign is important in pressuring organisations to make necessary changes rather than maintaining the status quo. 


\section{Backlash, Whiplash, and the Idle No More Movement}

In 1991 Susan Faludi published the first edition of Backlash: The Undeclared War against American Women. Fauldi (1991, p.10) details through an in-depth presentation and analysis of then-current research

a powerful counterassault on women's rights, a backlash, an attempt to retract the handful of small and hard-won victories that the feminist movement did manage to win for women...[that] stands the truth boldly on its head and proclaims that the very steps that have elevated women's position have actually led to their downfall."

She carefully links that backlash to a "closed system that starts and ends in the media (Fauldi 1991, p.6). The work was significant because it not only provided a much-needed analysis, but it also documented historical trends indicating that when women make positive sociopolitical and cultural advancements toward dismantling systemic sexism, there is inevitably a misogynistic backlash. In the second edition, fifteen years after the first printing, Faludi (2006) introduces the book by asking herself the question "Is there still a backlash"? Her answer is that no there isn't, there is something worse.

Drawing from Faludi's concept of backlash, co-author and Cree scholar Alex Wilson (2010) describes her understanding of what that "something worse" might be. Wilson analyses and discusses how continued efforts to undermine feminism have a particular and specific effect on the lives and bodies of Indigenous women and two-spirit people. Wilson purports that the sexualisation and normalisation of violence in North America leads to "whiplash" or a negative reaction to positive advancements in Indigenous, queer, and environmental rights. That is, Indigenous women and two-spirit people feel the brunt of the force of an intersectional whiplash. There is precision, targeting and physical violence of a whip cracking (Wilson 2010). This is something that organisers of Idle No More and other recent social media campaigns know all too well. As the \#ChangeRedmen campaign gained more visibility, the attacks via social media on individual women and two-spirit people who were part of the campaign increased (E. Lee, personal communication June 2013; S. McLean, personal communication June 2013; Wilson 2015). The topic of Indigenous feminisms itself became a target both of mainstream whiplashers and even within Indigenous communities on Facebook, on Twitter, on online commentary and in real life.

Within the first few months of Idle No More, it was clear that not only had the movement reached global proportions (Full Duplex 2013), but there were continued efforts to undermine the tremendous advancements that INM was able to accomplish in such a short period of time. The success of the \#ChangeRedmen campaign without a doubt was linked to the increased visibility of Indigenous women and two-spirit people on social media and the power and momentum that INM was catalysing. The people who did the first work on both the \#ChangeRedmen campaign and INM were women and two spirit people who skillfully used social media. With them came their networks which included more women and two spirit people.

The whiplash effect reinforces settler-colonial domination and perpetuates supremacy of white, straight male and cisgendered bodies (Student Teachers Anti-Racism Society 2011; Wilson 2010). And because of this, the existence and vocal presence of Indigenous women and two-spirit people is a constant threat to these systems of domination. An analysis of the first six months of Idle No More by Full Duplex (2013) focused on the social media aspects of the movement and provided analysis and commentary on the power of the then-young movement:

The significance of INM cannot be downplayed. INM is a grassroots movement that leveraged the power of the participatory web and "open source" ideology. It is an energy source, which has united people of different communities. Tweets, Facebook Pages, podcasts, blog posts, forums, images, and videos built new bridges and obstructed traffic on others. Competition for attention is fierce and INM managed to do more than simply get noticed (Full Duplex 2013, p.1). 
Full Duplex provides graphs highlighting the correlation between increases in Tweets with the initiation of specific INM campaigns. For example, January 2013 was categorised as a period of high engagement with well over 500 Tweets per day mentioning the phrase Idle No More. During this month, there were a number of national and international campaigns such as the National Day of Action (known as \#J11) with 265 INM events that took place around the globe and over 60,000 Tweets on that day, on the January global day of action (\#J28), and other coordinated days of action. The Idle No More communications team has similarly documented that peaks in social media (Twitter and Facebook mentions) correlate with specific campaigns (McAdam, Wilson, \& Case 2016). \#ChangeRedmen was one such campaign.

The Full Duplex (2013) report provides in-depth discussion of the gender breakdown of social media. The general trend was that women were supporting and posting positive messages about the movement while men comprised a majority of the negative social media commentary, or were predominantly driving the whiplash. Significantly, however, for the first time in history a worldwide social movement was being informed and lead by Indigenous women (Full Duplex 2013).

\section{The Gendering of the Campaign}

The [\#ChangeRedmen] campaign may have gone differently if there was a man out front. A lot of the dissenting comments we received were about the group being "too sensitive" and "too emotionally attached to the issue." In fact, the very first news article published about our campaign set the tone, with the unfortunate headline "Redmen Team Name Irks Saskatoon High School Graduate," something I never lived down as my friends joked "Watch out, Erica is irked!" poking fun at how the school, the school board, and some media tried to downplay our anti-mascot campaign as nothing more than the boredom of one emotionally-driven young girl (Lee 2015).

This campaign took place in Saskatoon-Treaty 6 Territory, Neyinoway Askik (Cree Territory), and Métis homeland-a colonial space much like the rest of the Canadian state where heteronormativity and patriarchy are naturalised through organisational, familial, and institutional discursive practices (St. Denis 2007; Thobani 2011). Furthering the whiplash (Wilson 2010), the individualisation and feminisation of the campaign as "emotional" by the mainstream media marked it as inferior and not to be taken seriously. This occurred frequently as articles regarding the campaign focused on Erica Lee describing her as "irked" and noting her tears during interviews. These tropes of female/emotional/subordinate were juxtaposed with the construction of the mascot as a male/fierce/dominant embodying particular forms of masculinity and reproducing a gender binary. The "Redmen" mascot is the face of an Indigenous man-a red, feathered caricature of a man's head. This representation of Indigenous masculinity is made to be recognisable by the broader society-an image used in sports culture because it evokes discourses of stoicism, strength and an opponent to be feared. The feminisation of the \#ChangeRedmen campaign as "emotional" worked to govern subjects that were invested in this performance of racialised masculinity, and bring shame or emasculating those working against it.

The mascot social media campaign was one form of intervention into the white supremacy reproduced within the school and community. Many individuals, particularly white males in positions of authority, were resistant to the idea that Indigenous people should have control over how they are represented, particularly in the media (Full Duplex 2013). In a white supremacist society, white settlers are socialised into practices that maintain state control through both individual and institutional mechanisms. These discursive practices naturalise white heteropatriarchy and are used to discipline bodies into subjugation. Control over racist texts such as the "Redmen" mascot is fiercely protected by those who benefit most from the maintenance of inequitable power relations. From the onset, the Indigenous women on the campaign team experienced both racialised and sexualised violence from individuals who enacted the protection of the mascot by attacking the women leading the campaign. As Lee (2015), who was one of the administrators of the \#ChangeRedmen Facebook page, explains: 
There were comments with gendered, racialized slurs left on our group's page with regularity, directed at the women involved, sometimes using our names and including personal information, like our locations of work and school.

I'm only now starting to think about the implications of notions of masculinity conjured by sports mascots and what it meant for our little group of primarily Indigenous \& nonIndigenous women to challenge those notions. What does it do to challenge that silently stoic cartoon "Redman" face and replace it with an image of real-life Indigenous women saying no?

An example of the violent backlash against the campaign is provided below in a screenshot from the "Bedford Road 'Redmen,' It's Time for a Change" Facebook page:

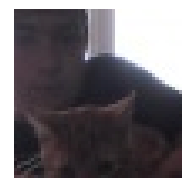

So you delete a bunch of my comments because i bring up facts, that prove this is all just bullshit? Get fucked. None of it was hateful or racist. This is bullshit. Quite being an attention whore pussy bitch, it's not gonna happen. people have tried before, get the fuck over yourself. I wasn't hateful before, but now i am.

\section{Like " Comment " 16 hours ago}

Figure 2: Comment on the It's time for change Facebook page.

In this excerpt, the writer employs racist and sexist language as a means to regulate and silence those involved in the campaign against the mascot. Discourses such as "attention whore pussy bitch" and other gendered/sexualised terms are derogatory threats that might protect the mascot as a symbol that upholds white heteropatriarchy. Each of these discourses is constructed as abject subjects-terms that historically have been used to mark bodies as degenerate and inferior. This individual's use of the term "attention whore" also shows how the attention the \#ChangeRedmen campaign was receiving on social media was a threat to the life and longevity of the Indigenous mascot. Although many of the violent responses like this one were from teenagers (high school age), these youth were already socialised into whiteness and performing violence to protect the social order.

\section{Institutional Mechanisms of Control}

The individuals who campaigned to keep the mascot performed multiple moves to settler innocence: in particular, the upholding and weaponising of a small number of Indigenous voices that explicitly conformed to their wishes to keep the mascot and the attempted delegitimisation of anyone who supported the \#ChangeRedmen campaign. The high percentage of Indigenous people who spoke out against the mascot affected the dynamics of the mascot debate in this space, because Indigenous people were not invisibilised. One of the strategies of school systems and athletic clubs is to frame the mascot issue by focusing on the tensions between Indigenous groups that disagree. The most common tactic is to label and divide Indigenous people into 'academic Indians vs pow wow Indians,' with the presumption that academics are anti-mascot, while 'traditional' people support it. These discourses, false binaries, legitimised anyone upholding the logo as speaking from a position of authority and authenticity, while suggesting that those against the logo were influenced by the colonial system of academe. These colonial tropes suggest that Indigenous people who support the logo are 'real Indians,' while marking all Indigenous people who engage in contemporary resistance as illegitimate (Farnell 2004; St. Denis 2004). These tactics of divide and conquer exasperated tensions in the Indigenous community regarding the mascot.

It must be noted that the historical and ongoing erasure of Indigenous people from positions of power in colonial institutions and positive representations in texts such as mass media, education, and government often leads to a desire from some Indigenous people to maintain Indigenous mascots. This hinges on the belief that some visibility and representation (in the guise of an honour) is better than none at all. Our campaign insisted that Indigenous people 
can and will decide how they are represented to the public, in particular moving away from the violence of stereotypical and objectified symbols and signs.

The actions to uphold the discourses that constructed the mascot as an honour created a hostile environment for everyone in the school and community that supported the campaign. As Farnell (2004, p49) contends:

This racializing discourse [of honouring] empowers whites, not only to claim a superior right to determine the representations but also to silence Native voices, insisting with neocolonial impunity that whites will determine what Indians will mean for this community. These indirect indexes reveal the institutionalized racism at work here.

These tensions were heightened during the whiplash to our social media campaign, which caused many people to feel uncomfortable about supporting our anti-mascot campaign. We encouraged school boards and community organisations to engage in critical antiracist education with their members. We believe that education is key to understanding how Indigenous mascots normalise racism and sexism in our society. In fact, one of the school board members that voted to retire the mascot publicly admitted that reading the research on Indigenous mascots influenced his decision to ban the mascot.

There were many public letters of support shared on the campaign's social media from various individuals and institutions throughout the province, such as a letter from the Department of Educational Foundations at the University of Saskatchewan, which called for the mascot to be banned and antiracist education for the school and community:

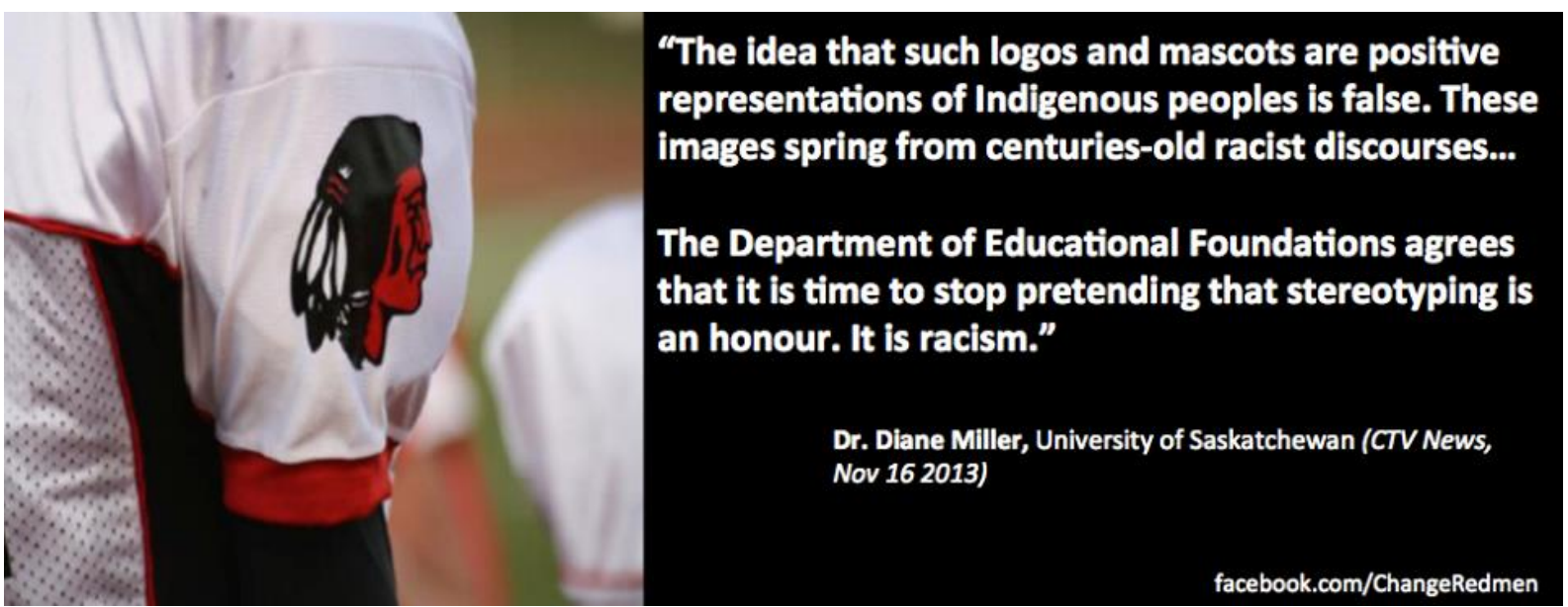

Figure 3: Post by Department of Educational Foundations at the University of Saskatchewan

This growing solidarity with the campaign helped to educate the broader public and put pressure on the school board to ban the racist mascot.

\section{Non-Violent Direct Action}

In 2013, a group of people who were part of the campaign, including Indigenous drummers, gathered to protest the "Redmen" mascot at an invitational basketball tournament, a prominent annual high school sporting event. Two of the Indigenous women who were a highly visible part of the campaign tried to buy tickets for the event, but were turned away while the three white allies that were with them were allowed entrance. Outside the school, there were multiple police cars and officers patrolling. One of the white allies shared the following account of the night on Facebook:

We were treated like terrorists in possession of lethal weapons (our posters, our message). I can't believe I was told by a guy who spoke highly of his participation in Idle No More rallies in Ottawa that "you'll never win" if we are trying to change his high school's mascot. It was sad to know he was the same person that turned away all our 
drummers. However, this was all fuel to the cause and I am glad we made our presence known. This is about resistance, coming together, and overcoming this kind of racist oppression. Props to everyone who came out and also to those who were there in spirit.

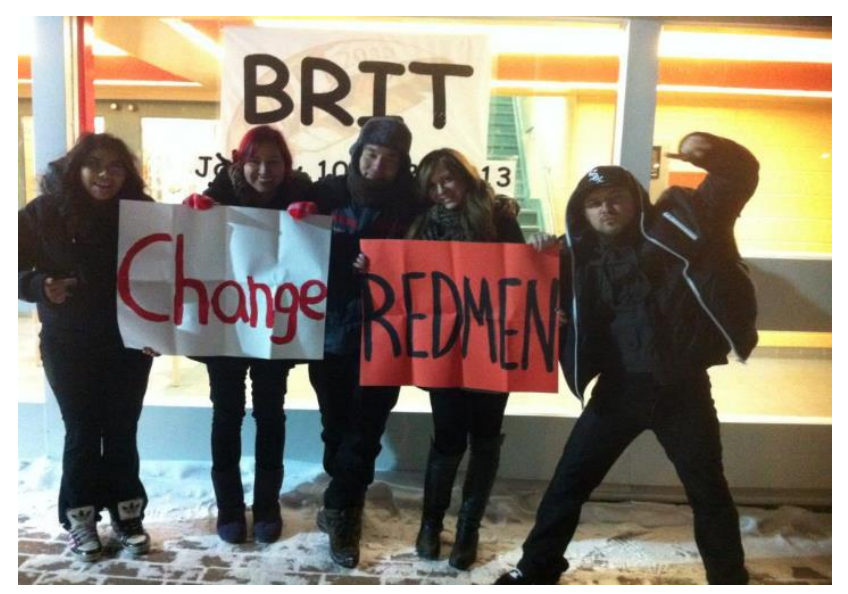

Figure 4: Youth representing the \#ChangeRedmen campaign

The ways in which the school board used surveillance and control at the basketball tournament to deter the right to publicly protest shows the powerful impact of non-violent direct actions by a small number of people. The plan that the youth representing the \#ChangeRedman campaign has was simply to hold up signs-what could be so threatening about this act? The simple act of holding a sign can at once turn the gaze and denaturalise the racist Indigenous mascot that is central to an event celebrated predominantly by white settlers. As Lee (2015) explains:

The hardest part of this work is listening to the stories of Aboriginal youth who dare to speak out against stereotypes and faced ostracism as a result. In January, a student from a local high school, stood up at Bedford Road's basketball tournament with a sign that said, "We are people, not mascots." He was booed by hundreds of basketball fans before being escorted out of the school, demonstrating that there is a certain type of "red man" that is acceptable (a cartoon) and one that is not (a living person with a voice). To me, that is a real warrior.

Non-violent direct actions such as these often have detrimental effects on both the resistors involved who face colonial violence, as well as those people that are witnessing the intervention who may want to speak up. The lesson is this: you will face public anger and shame if you speak out against racism in your school and community. The significance of using both social media and non-violent direct actions to disrupt the dominant discourses surrounding the text of the mascot cannot be underestimated.

\section{The Retirement: White Tears}

In a vote of 8 to 2 on March 4, 2014 the Saskatoon Public School Board voted to respectfully retire the racist "Redmen" mascot (Saskatoon Public Schools 2014). In an interview with CTV news, the school administration said that retiring the mascot was "like losing a member of the family" (Young 2014). The tensions between groups that advocate for the mascot, and those who campaign against them are often high. This is because of the emotional investment that white settlers have in racial significations such as an Indigenous mascot. Individuals who fight to maintain mascots often exhibit a range of emotion such as anger, fear, frustration and sadness. When other mascots are replaced with an updated logo, there is no outcry. Indigenous mascots are an emotional investment for white settlers because the mascot represents white identity, not Indigeneity. Whiteness is co-constructed with Indigeneity, and one of the many ways this construction is reified is through the stereotypically racist images of Indigenous people. In this way, the text of the Indigenous mascot comes to represent white supremacy. 
The spectacle of Indigenous mascots represents the colonisers fantasy of racial superiority. As King states:

Accounts of the history and significance of such metaphoric recyclings rightly underscore the articulations of power, representation, and racialization, unpacking the ways whites have used (enacted, really) signs of difference to formulate identities, craft community, author national narratives, and consolidate racial hegemony (2004, p.193).

There is still much educational work to do in order to build a public consciousness that includes a critical analysis of white settler colonialism, and how racist symbols such as Indigenous mascots are dehumanising and violent. Although the "Redmen" mascot was finally retired, white settlers continue to resist any commitment to build safer spaces in schools for Indigenous students through antiracist education. We suggest that this is how white supremacy is reproduced in the face of a successful campaign to dismantle and eradicate racist images of Indigenous peoples.

\section{Conclusion}

This paper examines how social media created a powerful space for Indigenous peoples' refusal through a campaign that sought the retirement of a racist Indigenous mascot. The primary intervention of our campaign was the use of antiracist education on social media in order to build mass critical consciousness and a network of support. The significance of our social media campaign as a space for Indigenous and antiracist pedagogy specifically lead by Indigenous women and two-spirit people cannot be underestimated. In a colonial context, Indigenous peoples have been marginalised by white institutions such as the mass media, and social media provides a public space that directly challenges this regulation and control, as it is increasingly accessible to Indigenous peoples worldwide. We suggest that the use of social media created a campaign that was powerful enough to lead to the ban of a racist mascot after unsuccessful attempts by many other groups.

\section{Acknowledgements}

The authors would like to acknowledge the many people who contributed to retiring the mascot, before and during the \#ChangeRedMen campaign. We would also like to acknowledge and thank Anna Lee Popham Smith, Jaylene Murray and Janet Sarson for providing feedback on drafts of this paper.

\section{Funding}

Partial funding to support this writing was provided by SSHRC grant 435-2014-1488.

\section{References}

American Psychological Association. (2005, October 18) "APA Resolution Recommending the Immediate Retirement of American Indian Mascots, Symbols, Images, and Personalities by Schools, Colleges, Universities, Athletic Teams, and Organizations". Available at, https://www.apa.org/about/policy/mascots.pdf [Accessed 31 January 2017].

American Psychological Association. (n.d.) "Summary of the APA Resolution Recommending Retirement of American Indian Mascots". Available at, http://www.apa.org/pi/oema/resources/indian-mascots.aspx [Accessed 31 January 2017].

Baca, L.R. (2004) "Native Images in Schools and the Racially Hostile Environment", Journal of Sport \& Social Issues, 28(71). doi: dx.doi.org/10.1177/0193732503261149

Baym, N.K. \& Boyd, D. (2012) "Socially Mediated Publicness: An Introduction”, Journal of Broadcasting \& Electronic Media, doi:dx.doi.org/10.1080/08838151.2012.705200 
Carlson, B. (2016) "For Aboriginal and Torres Strait Islander People, What Are the Health Impacts of Social Media", Croakey. Available at, https://croakey.org/for-aboriginaland-torres-strait-islander-people-what-are-the-health-impacts-of-social-media/ [Accessed 31 January 2017].

Carlson, B. \& Frazer, R. (2016) "Indigenous Activism and Social Media: The Global Response to \#SOSBLAKAUSTRAIA”. In McCosker, A., Vivienne, S., \& Johns, A. (eds.), Rethinking Digital Citizenship: Control, Contest and Culture, pp. 115-130, Rowman and Littlefield International, England.

CBC News. (2014, January 12) "Redskins Name Scrapped by Ottawa Minor Football Club" Available at, http://www.cbc.ca/news/canada/ottawa/redskins-name-scrapped-byottawa-minor-football-club-1.2493697 [Accessed 31 January 2017].

Crowe, R. \& Wilson, A. (2015) "Idle No More Round Dance Revolution at the Hemispheric Institute of Performance: A Discussion with Roewan Crowe and Alex Wilson", Caribbean Rasanblaj, 12(1). Available at, http://hemisphericinstitute.org/hemi/en/emisferica121-caribbean-rasanblaj/crowe [Accessed 5 May 2017].

Davis-Delano, L.R. (2007) "Eliminating Native American Mascots: Ingredients for Success", Journal of Sport \& Social Issues, $\mathbf{3 1 ( 4 ) : 3 4 0 - 3 7 3 .}$ doi:dx.doi.org/10.1177.0193723507308251

Dei, G., Karumanchery, L., \& Karumanchery, N. (2005) Playing the Race Card: Exposing White Power and Privilege, Peter Lang, New York, NY.

Dei, G. (1995) "Integrative antiracism: Intersections of race, class and gender", Race, gender \& class: Perspective on Canadian Antiracism, 2(3): 11-30.

Education Week. (1988) "Minnesota Districts Asked to Drop Indian Team Names". Available at, http://www.edweek.org/ew/articles/1988/o6/o1/x36state.ho7.html [Accessed 5 May 2017].

Faludi, S. (1991) Backlash: The Undeclared War against American Women, Crown Publishing Group, Danvers, MA.

Farnell, B. (2004) “The Fancy Dance of Racializing Discourse”, Journal of Sport and Social Issues, 28(1):30-53.

Foucault, M. (1995) Discipline and Punish: The Birth of the Prison (A. Sheridon, Trans), Vintage Books, New York, NY.

Francis, D. (1992) The Imaginary Indian: The Image of the Indian in Canadian Culture, Arsenal Pulp Press, Vancouver, BC.

Fryberg, S.A., Markus, H.R., Oyserman, D., \& Stone, J.M. (2008) "Of Warrior Chiefs and Indian Princesses: The Psychological Consequences of American Indian Mascots", Basic $\begin{array}{lll}\text { and Applied Social Pschology, } & \text { 30(3):208-218. }\end{array}$ doi:dx.doi.org/10.1080/01973530802375003

Full Duplex. (2013, June) "Idle No More at Six Months: An Analysis of the First Six Months of the Idle No More Movement". Available at, http://digitalpublicaffairs.com/wpcontent/uploads/2013/o6/IdleNoMoreAtSixMonths.pdf [Accessed 31 January 2017].

Gould, S. (1981) The Mismeasure of Man. W.W. Norton and Company, Boston, MA.

hooks, b. (1992). “The Oppositional Gaze: The Black Female Spectator" Black Looks, Race and Representation, pp. 115-131, South End Press, Boston.

Inter-Tribal Council of the Five Civilized Tribes. (2001) "The Five Civilized Tribes Intertribal Council Mascot Resolution”. Available at, http://aistm.org/2001.civilized.tribes.htm [Accessed 31 January 2017]. 
King, C.R. (2004) "This is Not an Indian: Situating Claims about Indianness in Sporting Worlds", Journal of Sport and Social Issues 28:3-10. doi:dx.doi.org/10.1177/0193732503261147

King, C.R. (2015) “American Indian and Nickname Changes: A Chronology”. In C.R. King (ed.), The Native American Mascot Controversy: A Handbook, pp.259-264, Lanham, MA, Rowman \& Littlefield Publishing Group, Inc.

Kino-nda-niimi Collective. (2014) The Winter We Danced: Voices from the Past, the Future, and the Idle No More Movement, ARP Books, Winnipeg, MN.

Leavitt, P.A., Covarrubias, R., Perez, Y.A., \& Fryberg, S.A. (2015) “'Frozen in Time': The Impact of Native American Media Representations on Identity and Self-Understanding", Journal of Social Issues, 71(1)39-53. doi:dx.doi.org/10.1111.josi.12095

Lee, E.V. (2014, May 10) "Change(d) the Name: Challenging "Savage" Stereotypes and Native Sports Mascots" [Blog post], Moontime Warrior. Available at, https://moontimewarrior.com/2014/05/10/changed-the-name-challenging-savagestereotypes-and-native-sports-mascots/ [Accessed 31 January 2017].

Lee, E.V. (2015, March 8) "Reflections on 'Redmen' and Indigenous Women's Organizing” [Blog post], Moontime Warrior. Available at, https://moontimewarrior.com/2015/03/o8/reflections-on-redmen-and-indigenouswomens-organizing/ [Accessed 31 January 2017].

Los Angeles Times. (2013, December 13) "Change Makers". Available at: https:www.pressreader.com/usa/los-angeles-times/20131215/282346857623007 [Accessed 5 May 2017].

McAdam, S., Wilson, A., \& Case, P. (2016) "Idle No More: Current Projects and Future Visions". Presentation at the Native American Indigenous Studies Conference, Honolulu, HI.

McLean, S. (2016) Disturbing Praxis: a Foucauldian Analysis of Student Subjectivities and Classroom Pedagogies in Public Schools. Doctoral Dissertation. University of Saskatchewan, Saskatoon, SK.

Mulvey, L. (1974). "Visual Pleasure and Narrative Cinema”, Screen (16)3, 6-18.

National Collegiate Athletic Association (NCAA). (2005) "NCAA Executive Committee Issues Guidelines for Use of Native American Mascots at Championship Events". Available at, http://fs.ncaa.org/Docs/PressArchive/2005/Announcements/NCAA\%2BExecutive\%2 BCommittee\%2BIssues\%2BGuidelines\%2Bfor\%2BUse\%2Bof\%2BNative\%2BAmerican \%2BMascots\%2Bat\%2BChampionship\%2BEvents.html [Accessed 31 January 2017].

Razack, S. (1998) Looking White People in the Eye: Gender, Race and Culture in Courtrooms and Classrooms, University of Toronto Press, Toronto, ON.

Said, E.W. (1979) Orientalism. Vintage Books, New York, NY.

Saskatoon Public Schools. (2014) Meeting Minutes of the Board of Education of the Saskatoon School Division No. 13 of March 4, Saskatchewan. Available at, http://www.saskatoonpublicschools.ca/Board/meetings/Minutes/mar414\%20regular. pdf [Accessed 3 May 2017].

Schnurr, J. (2013, September 3) "Ottawa man files human rights complaint against Nepean Redskins" CTV Ottawa. Available at: htto://Ottawa.ctvnews.ca/Ottawa-man-fileshuman-rights-complaint-against-nepean-redskins-1.143852 [Accessed 5 May 2017].

St. Denis, V. (2004). "Real Indians: Cultural Revitalization and Fundamentalism in Aboriginal Education”. In C. Schick, J. Jaffe, \& A.M, Watkinson (eds.), Contesting Fundamentalisms, pp. 35-47, Fernwood, Halifax, NS. 
St. Denis, V. (2007) "Feminism is for Everybody: Aboriginal Women, Feminism and Diversity". In J. Green (ed.), Making Space for Indigenous Feminisms, pp. 33-52, Fernwood, Halifax, NS.

Staurowsky, E.J. (2007) "You Know, We Are All Indian: Exploring White Power and Privilege in Reactions to the NCAA Native American Mascot Policy", Journal of Sport and Social Issues 31(1):61-76.

Sterzuk, A. \& Mulholland, V. (2011, Spring) "Creepy White Gaze: Rethinking the Diorama as a Pedagogical Activity”, Alberta Journal of Educational Research 57(1):16-27.

Strong, P.T. (2004) "The Mascot Slot: Cultural Citizenship, Political Correctness, and PseudoIndian Sports Symbols”, Journal of Sport and Social Issues 28:79-87.

Student Teachers Anti-Racism Society. (2011, May) "Student Teachers Anti-Racism Society (STARS) Educational Resource”. Available at, http://starsusask.blogspot.ca/2011/o5/interconnecting-isims-race-gender-and.html [Accessed 31 January 2017].

Thobani, S. (2011) Exalted Subjects: Studies in the Making of Race and Nation in Canada, University of Toronto Press, Toronto, ON.

USA Today. (2013, September 24) "List of Schools that Changed Native American Nicknames". Available at, https://www.usatoday.com/story/sports/2013/o9/12/native-americanmascot-changes-ncaa/2804337/ [Accessed 5 May 2017].

U.S. Commission on Civil Rights. (2001, April 13) "Statement of U.S. Commission on Civil Rights on the Use of Native American Images and Nicknames as Sports Mascots". Available at, http://www.aics.org/mascot/civilrights.html [Accessed 31 January 2017].

Warren, J. (2005) "Bodily Excess and the Desire for Absence: Whiteness and the Making of (Raced) Educational Subjectivies”. In B. Alexander, G. Anderson, \& B. Gallegos (eds.), Performance Theories in Education: Power, Pedagogy, and the Politics of Identity, pp. 83-106, Erlbaum, Mahwah, NJ.

Wilson, A. (2010, September) "Whiplash: Interconnecting Isms, Race, Gender and Homophobia”. Presentation for STARS (Student Teachers Anti-Racism Society), College of Education, University of Saskatchewan, Saskatoon, SK.

Wilson, A. (2015) "A Steadily beating heart”. In E. Coburns (ed.) More Will Sing their Way to Freedom, pp.272-276, Fernwood, Winnipeg, MB.

Young, M. (2014, March 6) “Overwhelming Positive Vote on Team”, CTV Saskatoon. Available at,

http://saskatoon.ctvnews.ca/video?clipId=301773\&binId=1.1165954\&playlistPageNum $=1$ [Accessed 31 January 2017].

Zirin, D. (2015, July 2) "The Battle to Change the Mascots". Socialism 2015 interview with Erica Violet Lee and Suzan Shown Harjo. Available at, http://wearemany.org/a/2015/o7/battle-to-change-mascots [Accessed 5 May 2017].

Copyright: (C) 2017 McLean, Wilson \& Lee. This is an open-access article distributed under the terms of the Creative Commons Attribution-NonCommercial 3.0 Australia License, which permits non-commercial use, distribution, and reproduction in any medium, provided the original author and AJIS are credited. 


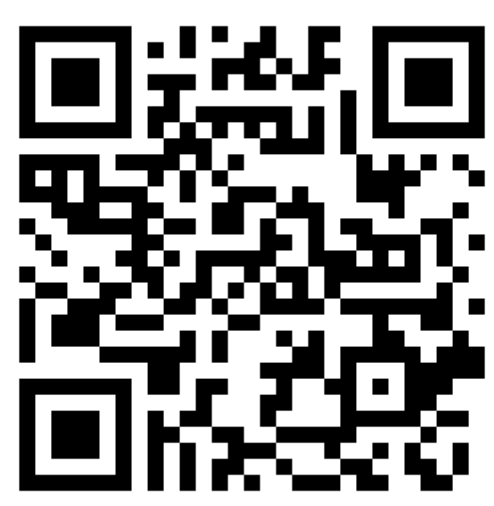

